\title{
Protective effect of Citrus macroptera fruit pulp juice rendering Nrf2-pathway against cisplatin-induced genotoxicity
}

\author{
Md. Mahmudul Hasan ${ }^{1 *}$, Rubait Hasan², Md. Rezuan Al Mahmud¹, Md. Gaziul Islam¹ \\ ${ }^{1}$ Molecular Biology and Protein Science Laboratory, Department of Genetic Engineering and Biotechnology, Faculty of Life and Earth Sciences, University \\ of Rajshahi, Rajshahi, Bangladesh. \\ ${ }^{2}$ Department of Biochemistry and Biotechnology, Khwaja Yunus Ali University, Rajshahi, Bangladesh.
}

\begin{tabular}{l}
\hline ARTICLE INFO \\
\hline Received on: $14 / 08 / 2018$ \\
Accepted on: $12 / 11 / 2018$ \\
Available online: $30 / 12 / 2018$ \\
\\
\hline Key words: \\
Cisplatin, oxidative stress, \\
Citrus macroptera, NQO1, \\
polychromatic erythrocytes, \\
sperm morphology.
\end{tabular}

\begin{abstract}
Citrus macroptera (Rutaceae) has long been used as an appetite stimulant and in the treatment of fever. Protective effect of $C$. macroptera against oxidative stress has studied but there is a lack of information concerning its role in antioxidant-related gene expression. Thus, this study was particularly aimed to investigate the protective effect of C. macroptera fruit pulp juice (CMFPJ) in anticancer drug cisplatin (CP)-induced genotoxicity. Male albino mice were treated with $2.5 \mathrm{mg} / \mathrm{kg} \mathrm{CP}(\mathrm{CP} 2.5)$ for five consecutive days. Recovery from genotoxicity was carried out by treating mice with 25 and $50 \mathrm{mg} / \mathrm{kg}$ CMFPJ for the next five consecutive days and treatments were given intraperitoneally (ip). The animals were sacrificed and polychromatic erythrocytes (PCE) with micronuclei (MN), the percentage of PCE, and sperm morphology were studied. In addition, the expression of nicotinamide adenine dinucleotide phosphate hydrogen (NADPH) quinone oxidoreductase 1 (NQO1); an antioxidant gene responsible for producing an enzyme that detoxifies chemical stressors was analyzed. CMFPJ significantly decreased $(p<0.05) \mathrm{MN}$ in PCE, \% of PCE, and sperm abnormalities. Besides, CMFPJ induced the expression of NQO1. The polyphenol, flavonoids, and vitamin-C present in CMFPJ synergistically showed the protective effect against CP-induced genotoxicity.
\end{abstract}

\section{INTRODUCTION}

Cisplatin (CP) is one of the most effective chemotherapeutic drugs widely used to treat various types of cancer in adults and children (Oliveira et al., 2009). Having a high therapeutic activity, this drug has various side effects, including nephrotoxicity and genotoxicity (Greene, 1992; Nersesyan et al., 2003).

The increasing awareness about the deleterious effects of anticancer drugs is influencing world research ground to find out remedies. Epidemiological surveys and laboratory investigations have made a strong demand on dietary agents for amelioration from genotoxic effects induced by anticancer drugs

\section{${ }^{*}$ Corresponding Author}

Md. Mahmudul Hasan, Molecular Biology and Protein Science Laboratory, Department of Genetic Engineering and Biotechnology, Faculty of Life and Earth Sciences, University of Rajshahi, Rajshahi, Bangladesh.E-mail:mahmudul_geb@yahoo.com
(Premkumar et al., 2006). Dietary antioxidants have well-built aptitude to reduce the toxic effects of chemotherapeutic drugs by preventing the accumulation of reactive oxygen species (ROS) (Conklin, 2000) and by scavenging ROS or enhancing endogenous antioxidant enzyme activity (Han et al., 2007).

As a potent source of antioxidants (Paul et al., 2015), C. macroptera fruit was used in this study. The citrus fruit C. macroptera belonging to the Rutaceae family is well known as "Satkara" in Bengali and "wild orange" in English. This semi-wild fruit is available in the hill tracks of the Sylhet division of Bangladesh and in some regions of India (Paul et al., 2016). C. macroptera contains $22.00 \mathrm{mg} \beta$-carotene, $0.08 \mathrm{mg}$ thiamine, $0.01 \mathrm{mg}$ riboflavin, $3.50 \mathrm{mg}$ sodium, $89.00 \mathrm{mg}$ potassium, $25.00 \mathrm{mg}$ calcium, $10.00 \mathrm{mg}$ magnesium, $0.15 \mathrm{mg}$ iron, $0.21 \mathrm{mg}$ zinc, $0.07 \mathrm{mg}$ copper, and $12.00 \mathrm{mg}$ phosphorus per $100 \mathrm{~g}$ dry weight (Islam et al., 2015). The fruit pulp was reported to contain an elevated amount of antioxidants, say $291.06 \mathrm{mg}$ of polyphenols, $145.02 \mathrm{mg}$ of flavonoids, 526.08 $\mathrm{mg}$ of tannin, and $120.83 \mathrm{mg}$ of vitamin-C per $100 \mathrm{~g}$ dry weight 
(Paul et al., 2015). C. macroptera is able to give considerable defense against lipid peroxidation in rat liver and kidney tissues because of its strong antioxidant properties (Paul et al., 2016). Considering the information mentioned above, this current study was undertaken to investigate the protective effect of $C$. macroptera fruit pulp juice (CMFPJ) against cisplatin-induced genotoxicity.

\section{MATERIAL AND METHODS}

\section{Chemicals and reagents}

Cisplatin was collected from Sigma-Aldrich (USA). TIANScript M-MLV (Moloney Murine Leukemia Virus) reversetranscription kit was bought from Tiangen (Beijing, China) and primers were custom synthesized from IDT (Integrated DNA Technologies, Malaysia). Other chemicals were of analytical grade.

\section{Collection and identification of $C$. macroptera fruits}

C. macroptera fruits were collected from a local market of Sylhet, Bangladesh. The collected fruit was authenticated by a taxonomist of Department of Botany, University of Rajshahi, Bangladesh and a reference specimen was deposited under accession number 00212 in the herbarium of the same department.

\section{Extraction procedure}

In order to collect the pulp, thick rind of $C$. macroptera fruit was removed with the gloved hand. Then, the pulp was cut into small pieces and juice was collected by squeezing the pieces of pulp with mechanical squeezer. The juice was dried to have sticky and concentrated extract which was dissolved in methanol and filtered by using glass fiber filter paper (Macherey-Nagel $\mathrm{GmbH}$, Germany) with DURAN ${ }^{\circledR}$ filtering apparatus (German) at room temperature. Finally, the filtrate was dried with VirTis BenchTop Pro freeze dryer (Sp Scientific, USA) to have almost powder form and stored at $-20^{\circ} \mathrm{C}$ for further use.

\section{Experimental animals}

Young male Swiss albino mice (Mus musculus, 8 weeks old) were obtained from the Department of Pharmacy, Jahangirnagar University, Savar, Dhaka, Bangladesh. They were maintained and acclimatized in a pathogen-free, a well-ventilated section of the animal house $\left(25^{\circ} \mathrm{C} \pm 2{ }^{\circ} \mathrm{C}\right.$ temperature and $\sim 70 \%$ humidity $)$ of the Institute of Biological Sciences, University of Rajshahi, Rajshahi, Bangladesh. Food and drinking water were provided ad libitum. All experiments were carried out in accordance with guideline approved by the Institutional Animal, Medical Ethics, Biosafety and Biosecurity Committee (IAMEBBC) for Experimentations on Animal, Human, Microbes and Living Natural Sources [(license no: 31/320-IAMEBBC/Institute of Biological Sciences (IBSc)], IBSc, University of Rajshahi, Rajshahi, Bangladesh.

\section{Experimental design and treatment procedure}

The animals were randomly allocated into eight groups ( $n=6)$; four for micronucleus (MN) assay while remaining for sperm morphology assay. The first group was served as control (CT) and administered with $200 \mu \mathrm{l}$ of physiological saline. Remaining groups were treated with $2.5 \mathrm{mg} / \mathrm{kg} \mathrm{CP}$ for five consecutive days to induce oxidative stress. Then, a group was left as a stressed group (CP 2.5). Third and fourth groups were treated with 25 and $50 \mathrm{mg} / \mathrm{kg}$ CMFPJ, respectively, for the next five consecutive days. All treatments were given by ip injection.

\section{Bone marrow isolation}

Bone marrow isolation was made as described previously (Lwin et al., 2016) with slight modification. The mice were anesthetized and hind limbs were separated. The femurs were dissected from the limbs by removing fat and muscles. The ends of the femur were cut off and placed in $0.5 \mathrm{ml}$ microcentrifuge tube with an open end at the bottom. The lid of the $0.5 \mathrm{ml}$ microcentrifuge tubes was cut off and tubes with bone were placed in the $1.5 \mathrm{ml}$ microcentrifuge tubes containing $500 \mu \mathrm{l}$ of PBS in each. Finally, bone marrow was isolated at room temperature by centrifuging ( $\mathrm{Z} 233$ M-2 Microliter Centrifuge, Hermle Labortechnik, GmbH) mouse femurs at 2,000 rpm for 2 minutes. Isolated bone marrow was subjected to Micro-nucleus (MN) assay and RNA isolation.

\section{Micro-nucleus assay}

The air-dried slides of bone marrow cell suspensions were stained as described previously (Gollapudi and Kamra, 1978). The overnight aged slide was fixed in absolute methanol for 5 minutes prior to washing with deionized water. Then the slides were stained in Giemsa (1:6 Giemsa in distilled water) for 10 minutes. Again the slides were washed thoroughly in deionized water, air-dried, and dipped into xylene for 3 minutes. Finally, the slides were mounted in DPX (a mixture of a polystyrene distyrene, a plasticizer tricresyl phosphate, and xylene). Slides (48 hours aged) were scored under an inverted microscope (Optika, Italy) at 40× magnification. To determine the frequency of micronucleated polychromatic erythrocytes (MNPCE), 1,000 polychromatic erythrocytes (PCE) were scored per mouse. Besides, normochromatic erythrocytes plus PCE per animal were scored for determining the $\%$ of PCE.

\section{Polymerase chain reaction}

Total RNA from bone marrow of mouse was isolated using RNA simple total RNA kit (Tiangen, Beijing, China) according to the manufacturer's protocol. RNA concentration and purity were measured by spectrometry at 260 and $280 \mathrm{~nm}$. Isolated RNA was then converted to cDNA using TIANScript M-MLV (Tiangen, Beijing, China) first-strand cDNA synthesis kit. For each reaction $(20 \mu \mathrm{l}), 2 \mu \mathrm{l}$ of $10 \mathrm{mM}$ oligo(dT), $2 \mu \mathrm{l}$ dNTPs $(10$ $\mathrm{mM}), 1 \mu \mathrm{g}$ RNA, and nuclease-free water up to $15 \mu \mathrm{l}$ were taken in polymerase chain reaction (PCR) tube and incubated at $70^{\circ} \mathrm{C}$ for 5 minutes. The mixture was immediately placed on ice for 2 minutes. M-MLV reverse transcriptase $(1 \mu \mathrm{l})$ and first strand buffer $(5 \times)(4 \mu \mathrm{l})$ were added to each tube and incubated at $45^{\circ} \mathrm{C}$ for 50 minutes. Then the mixture was incubated at $95^{\circ} \mathrm{C}$ for 5 minutes to inactivate the M-MLV reverse-transcriptase enzyme. Prepared cDNA was stored at $-20^{\circ} \mathrm{C}$ for further use. Qualitative expression of NQO1 gene was studied by PCR (SureCycler 8800, Agilent Technologies). Expression of NQO1 was normalized with an endogenous reference glyceraldehyde-3-phosphate dehydrogenase (GAPDH). The primer sequences were as follows: (1) NQO1: 
forward primer 5'-TTCTGTGGCTTCCAGGTCTT-3' and reverse primer 5'-AGGCTGCTTGGAGCAAAATA-3'; (2) GAPDH: forward primer 5'-GTGGAAGGACTCATGACCACAG-3' and reverse primer 5'-CTGGTGCTCAGTGTAGCCCAG-3'. Cycling condition was initial PCR activation step of 3 minutes at $95^{\circ} \mathrm{C}$, followed by 35 cycles of $95^{\circ} \mathrm{C}$ for 30 seconds, $50^{\circ} \mathrm{C}$ for 30 seconds, $72^{\circ} \mathrm{C}$ for 30 seconds, and a final extension of $72^{\circ} \mathrm{C}$ for 10 minutes. PCR products were analyzed on $1.5 \%$ agarose gel using Tiangen $1 \mathrm{~kb}$ plus DNA ladder (Tiangen, Beijing, China) as DNA marker and a gel documentation system (Red ${ }^{\mathrm{TM}}$ Imaging System, Alpha Innotech's).

\section{Sperm morphology assay}

On the $35^{\text {th }}$ day from the first day of exposure, the mice were sacrificed by cervical dislocation and their caudal epididymis was surgically removed. Sperm smears were prepared from the epididymis as previously described (Alabi and Bakare, 2011). For each mouse, 1,000 sperm cells were assessed for morphological abnormalities (Alabi and Bakare, 2011).

\section{Statistical analysis}

All results are demonstrated as the mean \pm standard deviation (SD). Statistical comparisons were done by one-way analysis of variance followed by Post Hoc Dunnett's T3 test using SPSS version 20. The results were considered significant at $p<0.05$.

\section{RESULTS}

\section{Micro-nucleus assay}

$\mathrm{CP}$ is well known to induce $\mathrm{MN}$ in PCE and to decrease the $\%$ of PCE. As shown in Table 1, CP significantly $(p<0.05)$ increased MNPCE and decreased \% of PCE in mice bone marrow. Whereas, CMFPJ significantly $(p<0.05)$ reversed the number of MNPCE and \% of PCE induced by $\mathrm{CP}$. The recovery effect of CMFPJ is dose-dependent.

\section{Polymerase chain reaction}

As observed in Figure 1, the expression of endogenous reference GAPDH is more or less equal in all groups and this is the indication that equal amount of RNA was used in cDNA synthesis. But the expression of NQO1 is not equal in all groups. $\mathrm{CP}$ decreased the expression of NQO1 compared to CT. While CMFPJ treatment induced the expression of NQO1 in a dosedependent manner.

\section{Sperm morphology assay}

As shown in Table 2, CP significantly $(p<0.05)$ increased sperm abnormalities in mice compared to CT. On the other hand, treatment with CMFPJ significantly $(p<0.05)$ reduced abnormal sperm count in a dose-dependent manner.

Table 1. Effect of CMFPJ on CP induced irregular PCE in mice bone marrow.

\begin{tabular}{lcc}
\hline Experimental groups & $\begin{array}{c}\text { MN-PCE } \\
(\text { mean } \pm \text { SD) }\end{array}$ & $\begin{array}{c}\text { PCE (\%) } \\
(\text { mean } \pm \text { SD) }\end{array}$ \\
\hline CT & $5.33 \pm 0.58$ & $55.67 \pm 4.69$ \\
CP 2.5 & $17 \pm 2.65^{\mathrm{a}}$ & $42.33 \pm 6.77^{\mathrm{a}}$ \\
CP $2.5+$ CMFPJ 25 & $9.67 \pm 1.53^{\mathrm{b}}$ & $47.33 \pm 3.72^{\mathrm{b}}$ \\
CP 2.5 + CMFPJ 50 & $7.67 \pm 1.15^{\mathrm{c}}$ & $51.33 \pm 5.63^{\mathrm{c}}$ \\
\hline
\end{tabular}

aSignificant $(p<0.05)$ over CT.

${ }^{\mathrm{b}, \mathrm{c}}$ Significant $(p<0.05)$ over CP 2.5 .

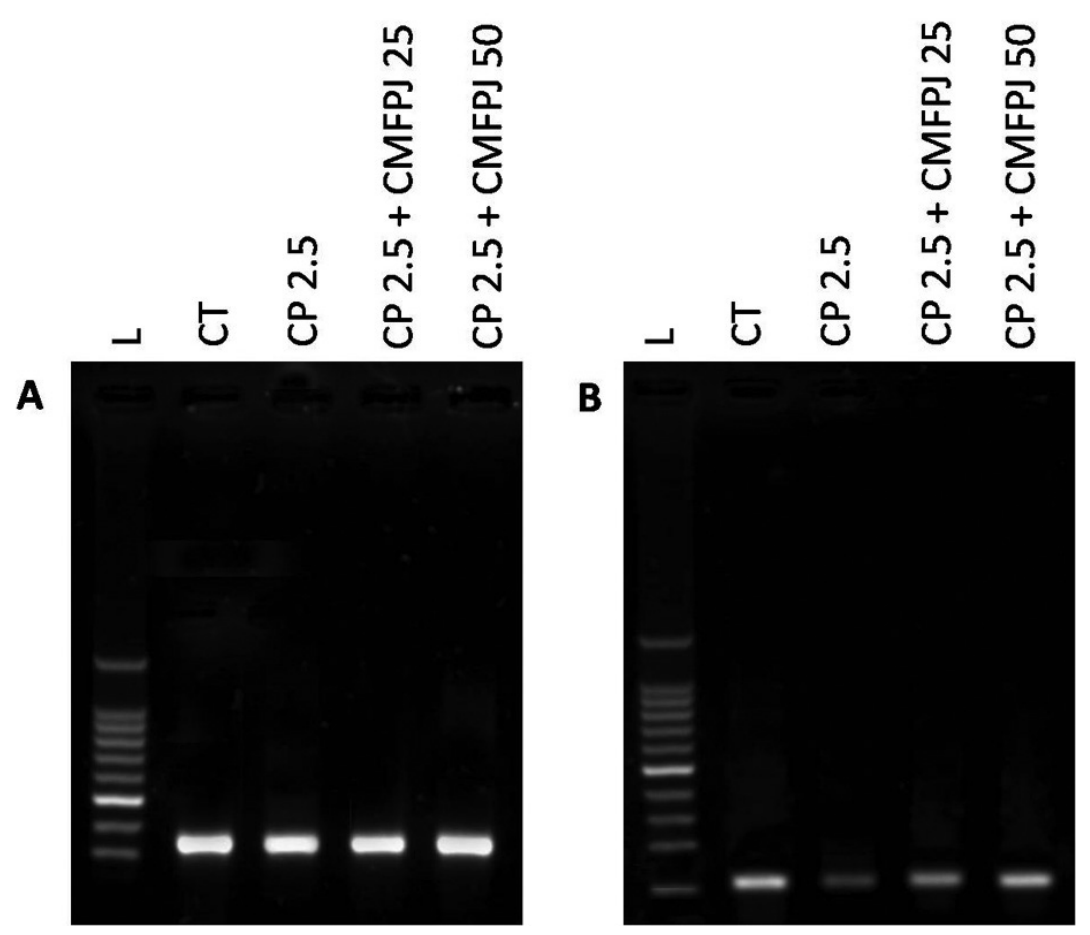

Figure 1. Effect of CMFPJ on NQO1 gene expression through PCR. The expression of NQO1 (B) was normalized by comparing with GAPDH (A) and was analyzed in mice bone marrow. 
Table 2. Ameliorative effect of CMFPJ on sperm abnormalities induced by cisplatin.

\begin{tabular}{lc}
\hline Experimental groups & Abnormal sperms (mean \pm SE) \\
\hline CT & $12.8 \pm 0.44$ \\
CP 2.5 & $53.4 \pm 1.64^{\mathrm{a}}$ \\
CP $2.5+$ CMFPJ 25 & $37.2 \pm 1.64^{\mathrm{b}}$ \\
CP $2.5+$ CMFPJ 50 & $16.6 \pm 0.44^{\circ}$ \\
\hline
\end{tabular}

asignificant $(p<0.05)$ over CT.

b,c Significant $(p<0.05)$ over CP 2.5 .

\section{DISCUSSION}

An imbalance between the generation of ROS and impaired antioxidant defense system results in oxidative stress. Oxidative stress generation is one of the key mechanisms involved in CP-induced cytotoxicity (Dasari and Tchounwou, 2014). However, CP-induced cytogenetic toxicity in mouse bone marrow was previously reported (Choudhury et al., 2000). Bone marrow with MNPCE and decreased \% of PCE are the well-established indicators of CP-induced cytogenetic toxicity (Choudhury et al., 2000; Misra and Choudhury, 2006).

Nuclear factor erythroid-2 related factor-2 (Nrf2) pathway is one of the most important mechanisms in a cell which protects from oxidative stress generated from endogenous or exogenous chemical stressors (Jin et al., 2015). Effective antioxidants try to optimize expression and translocation of Nrf2 gene into the nucleus under oxidative stress and bind to antioxidant response element that promotes expression of phase II detoxifying and antioxidant genes (Liang et al., 2013). NQO1 is one of the phase II detoxifying and antioxidant genes. NQO1 is known to encode NQO1; an antioxidant enzyme that detoxifies chemical stressors and provides cytoprotection. Once toxic quinines reduced by NQO1, they will conjugate with glutathione and eliminate from the cells. Based on this defensive aptitude of NQO1, the use of nutritive compounds to induce the expression of NQO1 has emerged as a promising strategy for oxidative stress prevention. Thus, we have particularly investigated the effect of CMFPJ in CP-induced oxidative stress.

Vitamin-C is ubiquitous and is an essential micronutrient for normal metabolic functions of the body but primates including humans do not have the ability to synthesize it (Chatterjee et al., 1995). For that reason, throughout chemotherapy, vitamin-C is supplemented to cancer patients in high doses (Misra and Choudhury, 2006). Interestingly, vitamin-C is anti-carcinogenic, anti-mutagenic, and anti-clastogenic (Aly and Donya, 2002; Halliwell, 1994; Khan and Sinha, 1994; Shamberger, 1984). As an important water-soluble antioxidant, it efficiently scavenges ROS (Chatterjee et al., 1995; Cozzi et al., 1997). The free radical scavenging aptitude of vitamin-C modulates the genotoxic effect of cancer chemotherapeutic drugs (Blasiak et al., 2003; Prasad, 2004). It is previously reported that flavonoids and polyphenols have the cytoprotective capacity (Ananthi et al., 2010; Kruawan and Kangsadalampai, 2006; Rathore, 2006).

However, NQO1 in mice bone marrow was induced by CMFPJ. Increased expression of NQO1 may be due to the synergistic effect of vitamin-C (Elbekai et al., 2007), flavonoids (Valerio et al., 2000), and polyphenols (Ross et al., 2000). Thus, increased expression of NQO1 has scavenged ROS
(Zhu and Li, 2012) and protects mice from the genotoxic effect of CP (Srijiwangsa and Na-Bangchang, 2017).

\section{CONCLUSION}

Our study suggests that $C$. macroptera is very much effective against oxidative insult. Thereafter, $C$. macroptera fruit juice can be recommended as potential dietary sources of antioxidants and also can be used to combat against genotoxicity induced by either cisplatin or any other genotoxic chemical.

\section{ACKNOWLEDGMENTS} in this study.

The authors would like to thank those people who helped

\section{CONFLICT OF INTEREST}

The authors have no conflict of interest.

\section{REFERENCES}

Alabi OA, Bakare AA. Genotoxicity and mutagenicity of electronic waste leachates using animal bioassays. Toxicol Environ Chem, 2011; 93:1073-88.

Aly FA, Donya SM. In vivo antimutagenic effect of vitamins C and $\mathrm{E}$ against rifampicin-induced chromosome aberrations in mouse bonemarrow cells. Mutat Res Genet Toxicol Environ Mutagen, 2002; 518:1-7.

Ananthi R, Chandra N, Santhiya ST. Protective effect of Hemidesmus indicus $\mathrm{R}$. Br. root extract against cisplatin-induced cytogenetic damage in mouse bone marrow cells. Genet Mol Biol, 2010; 33:182-5.

Blasiak J, Gloc E, Drzewoski J, Wozniak K, Zadrozny M, Skórski T, Pertynski T. Free radical scavengers can differentially modulate the genotoxicity of amsacrine in normal and cancer cells. Mutat Res Genet Toxicol Environ Mutagen, 2003; 535:25-34.

Chatterjee IB, Mukhopadhyay CK, Ghosh MK. Vitamin C: A potential saviour against free radical-induced oxidative damage. Curr Sci, $1995 ; 69: 747-51$.

Choudhury RC, Jagdale MB, Misra S. Cytogenetic toxicity of cisplatin in bone marrow cells of Swiss mice. J Chemothe, 2000; 12:173-82.

Conklin KA. Dietary antioxidants during cancer chemotherapy: impact on chemotherapeutic effectiveness and development of side effects Nutr Cancer, 2000; 37:1-8.

Cozzi R, Ricordy R, Aglitti T, Gatta V, Perticone P, De Salvia R. Ascorbic acid and beta-carotene as modulators of oxidative damage. Carcinogen, 1997; 18:223-8.

Dasari S, Tchounwou PB. Cisplatin in cancer therapy: molecular mechanisms of action. Eur J Pharmacol, 2014; 740:364-78.

Elbekai RH, Duke J, El-Kadi AO. Ascorbic acid differentially modulates the induction of heme oxygenase-1, NAD (P) $\mathrm{H}$ : quinine oxidoreductase 1 and glutathione S-transferase $\mathrm{Ya}$ by $\mathrm{As}^{3+}, \mathrm{Cd}^{2+}$ and $\mathrm{Cr}^{6+}$. Cancer Lett, 2007; 246:54-62.

Gollapudi B, Kamra OP. Applications of a simple Giemsastaining method in the micronucleus test. Mutat Res, 1979; 64:45-6.

Greene MH. Is cisplatin a human carcinogen? J Natl Cancer Inst $1992 ; 84: 306-12$

Halliwell B. Vitamin C: the key to health or a slow-acting carcinogen? Redox Rep, 1994; 1:5-9.

Han X, Shen T, Lou H. Dietary polyphenols and their biological significance. Int J Mol Sci, 2007; 8:950-88.

Islam MZ, Hoque MM, Asif-Ul-Alam SM, Monalisa K. Chemical composition, antioxidant capacities and storage stability of Citrus macroptera and Garcinia pedunculata fruits. Emir J Food Agric, 2015; 27:275-82.

Jin J, Li M, Zhao Z, Sun X, Li J, Wang W, Huang M, Huang Z. Protective effect of Wuzhi tablet (Schisandra sphenanthera extract) against cisplatin-induced nephrotoxicity via Nrf2-mediated defense response. Phytomed, 2015; 22:528-35. 
Khan PK, Sinha SP. Impact of higher doses of vitamin C in modulating pesticide genotoxicity. Teratog Carcinog Mutagen, 1994; $14: 175-81$

Kruawan K, Kangsadalampai K. Antioxidant activity, phenolic compound contents and antimutagenic activity of some water extract of herbs. Thai J Pharm Sci, 2006; 30:28-35.

Liang L, Gao C, Luo M, Wang W, Zhao C, Zu Y, Efferth T, Fu Y. Dihydroquercetin (DHQ) induced HO-1 and NQO1 expression against oxidative stress through the Nrf2-dependent antioxidant pathway. J Agric Food Chem, 2013; 61:2755-61.

Lwin ST, Edwards CM, Silbermann R. Preclinical animal models of multiple myeloma. Bonekey Rep, 2016; 5:1-9.

Misra S, Choudhury RC. Vitamin C modulation of cisplatininduced cytogenotoxicity in bone marrow, spermatogonia and its transmission in the male germline of Swiss mice. J Chemother, 2006; $18: 182-7$.

Nersesyan A, Perrone E, Roggieri P, Bolognesi C. Genotoxic action of cycloplatam, a new platinum antitumor drug, on mammalian cells in vivo and in vitro. Chemother, 2003; 49:132-7.

Oliveira RJ, Baise É, de Oliveira Mauro M, Pesarini JR, Matuo R, da Silva AF, Ribeiro LR, Mantovani MS. Evaluation of chemopreventive activity of glutamine by the comet and the micronucleus assay in mice's peripheral blood. Environ Toxicol Pharmacol, 2009; 28:120-4.

Paul S, Hossen MS, Tanvir EM, Islam MA, Afroz R, Ahmmed I, Saha M, Gan SH, Khalil MI. Antioxidant properties of citrus macroptera fruit and its in vivo effects on the liver, kidney and pancreas in wistar rats. Int J Pharmacol, 2015; 11:899-909.

Paul S, Islam M, Tanvir EM, Ahmed R, Das S, Rumpa NE, Hossen M, Parvez M, Gan SH, Khalil M. Satkara (Citrus macroptera) fruit protects against acetaminophen-induced hepatorenal toxicity in rats. Evid Based Complement Alternat Med, 2016; 2016:1-11.

Prasad KN. Multiple dietary antioxidants enhance the efficacy of standard and experimental cancer therapies and decrease their toxicity. Integr Cancer Ther, 2004; 3:310-22.
Premkumar K, Thirunavukkarasu C, Abraham SK, Santhiya ST, Ramesh A. Protective effect of saffron (Crocus sativus L.) aqueous extract against genetic damage induced by anti-tumor agents in mice. Hum Exp Toxicol, 2006; 25:79-84.

Rathore HS. A study on the cytological effects of Myrobalan (fruit of Terminalia chebula) in Allium tests. Ethnobot Leaflets, 2006; 10:92-7.

Ross D, Kepa JK, Winski SL, Beall HD, Anwar A, Siegel D. NAD (P) H: quinoneoxidoreductase 1 (NQO1): chemoprotection, bioactivation, gene regulation and genetic polymorphisms. Chem Biol Interact, 2000; 129:77-97.

Shamberger RJ. Genetic toxicology of ascorbic acid. Mutat Res Rev Genet Toxicol, 1984; 133:135-59.

Srijiwangsa P, Na-Bangchang K. Roles of NAD (P) H-Quinone Oxidoreductase 1 (NQO1) On Cancer Progression and Chemoresistance. J Clin Exp Oncol, 2017; 6:1-6.

Valerio Jr LG, Kepa JK, Pickwell GV, Quattrochi LC. Induction of human NAD (P) H: quinine oxidoreductase (NQO1) gene expression by the flavonol quercetin. Toxicol Lett, 2001; 119:49-57.

Zhu H, Li Y. NAD (P) H: quinine oxidoreductase 1 and its potential protective role in cardiovascular diseases and related conditions. Cardiovasc Toxicol, 2012; 12:39-45.

How to cite this article:

Hasan MM, Hasan R, Mahmud MRA, Islam MG. Protective effect of Citrus macroptera fruit pulp juice rendering Nrf2pathway against cisplatin-induced genotoxicity. J App Pharm Sci, 2018; 8(12): 067-071. 